\title{
Design for assembly meaning: a framework for designers to design products that support operator cognition during the assembly process
}

The original publication is available at www.springerlink.com: https://doi.org/10.1007/s10111-019-00588-x

\author{
Davy D. Parmentier ${ }^{1 *}$, Bram B. Van Acker ${ }^{1,2,3}$, Jan Detand ${ }^{1}$, Jelle Saldien ${ }^{1,3}$ \\ 1 Department of Industrial Systems Engineering and Product Design, Ghent University \\ Graaf Karel de Goedelaan 5, 8500, Kortrijk, Belgium \\ 2 Department of Personnel Management, Work and Organizational Psychology, Ghent University \\ Henri Dunantlaan 2, 9000, Ghent, Belgium \\ 3 imec-mict-UGent \\ De Krook, Miriam Makebaplein 1, 9000 Ghent, Belgium \\ * Corresponding author: davy.parmentier@ugent.be, orcid.org/0000-0002-5582-5195
}

Designing assembly instructions is mostly considered to be a non-designer task. Hence, in many companies, it is performed by production planners or instructional designers. However, analysing product components and looking for clues on how these components can be fitted together into a subassembly or final product is a fundamental part of assembly. Product designers play an important role in the way these components are perceived by the operator. This paper discusses the need and importance of a new approach to product design focused on how the assembly design can promote meaning to the operator, supporting operator cognition. The aim of this approach is to guide assembly operators more intuitively through their increasingly complex tasks. Doing so will allow them to avoid some of the major drawbacks that are present when using procedural instructions. Hence, this approach has the potential to decrease cognitive load and frustration, and increase mental wellbeing, work motivation and efficiency. As a first step towards this new approach, a conceptual framework is constructed, and insights are formulated after reviewing various design theories and concepts of design for meaning on their potential in a context of manual assembly.

Keywords: product design, manual assembly, meaning, cognition

\section{Introduction}

The aim of this paper is to provide insight on the potential of product design to provide cognitive support for operators during the assembly process by designing products that support the operator in the construction of an appropriate mental model of the assembly process. A framework is introduced that triggers the designer to consider the operator, the subassemblies, the components and the connections in relation to each other, and in relation to the relevant tools, jigs and fixtures, with a focus on intuitive assembly. The framework offers a set of questions for identification and insights on meaning in assembly, and formulates pathways to alter possibilities for action (i.e., affordances) or their perception. This offers a new perspective to overcome some of the drawbacks and problems linked to operator cognition in manual assembly.

\subsection{Increasing complexity}

In the past few decades, there has been an increasing demand for products meeting the need of a small group or even a single user. This has resulted in a shift from mass production to mass customization (Pine 1993). This demand is still increasing, and is leading to an increased product variety (Um et al. 2017, Wan and Sanders 2017) and hence 
also to unique production processes which in turn lead to an increasingly complex manufacturing process (Elmaraghy et al. 2012, Hu et al. 2008). Today, this complexity is one of the most important challenges, not only for production companies (Elmaraghy et al. 2012) but also for workers, who are confronted with ever-growing cognitive demands. These demands have increased as a result of the combination of the widespread automation of simple work routines and the associated shift towards more cognitive demanding tasks (Rasmussen 2000), as well as by an growing amount of product models and increased product variety (Claeys et al. 2015). Due to this variety, industrial workplaces are gradually transforming into small-batch, knowledge-driven workplaces (see. Young et al. 2015; Brolin et al. 2017; Longo et al. 2017). In these workplaces manual assembly is still important (due to its extreme flexibility [Booker et al. 2005], and its ability to assemble a wide variety of products and product families [Bley et al. 2004]). High-mix low-volume assembly or lot-size one (i.e., where only one unique, custom made product is produced) are the situations in which human flexibility is needed most. To tackle this demand for mass customised products, industrial manufacturing is becoming more and more closely linked to modern communication and information technologies in order to improve efficiency and flexibility. Furthermore, according to Hollnagel (2012), human involvement is also essential in modern technological systems because humans are able to interpret, detect and correct when mistakes occur. The digitalisation and integration of information through new communication technologies in industrial manufacturing, which results in cyber-physical manufacturing systems, is usually referred to as 'Industry 4.0 '. In the context of this Industry 4.0 workplace, more specifically the assembly, Erol et al (2016) have described a situation in which various products (lot-size one) could be assembled by the operator, supported by digital assistance systems, intelligent assembly technologies and collaborative robots. In their scenario, the assembly process itself is also monitored, and operators are provided with context- and situationsensitive support; errors are indicated and the information needed to correct them is provided. The information system described in this scenario is also in line with the systems described by Schuh et al. (2017) for Industry 4.0 (i.e., in their 6th maturity stage in which self-learning information processing based on automated data analysis and the delivery of contextualized information through task-specific user interfaces are made possible). This accommodates operators' desire to acquire the appropriate amount of information when they need it (Johansson et al. 2017b). These new technologies also open up opportunities for more operator-centred approaches, and stimulate us to reconsider the way assembly information is transferred. This is important because today, assembly instructions in industry are still (more or less) procedural, which has some important drawbacks.

\subsection{Drawbacks of procedural instructions}

A wide array of research has shown how procedural instructions can be designed to tackle the increasing cognitive demands of complex work environments. Eiriksdottir and Catrambone (2011), for instance, have investigated a number of different types of instruction, and how these can (or cannot) enhance performance, learning and transfer of procedural tasks. Ganier (2004) analysed factors that affect the processing of procedural instructions and its consequences for document design. Furthermore, various ways of presenting information and communicating instructions in a pictorial (Schumacher 2007, 2013) or static or dynamic way (Wong et al. 2009; Höffler and Leutner 2007; Ganier and De Vries 2016; Castro-Alonso, Ayres, and Paas 2016) or by using new media such as augmented reality (Radkowski, Herrema, and Oliver 2015; Syberfeldt et al. 2015; Loch et al. 2016; Re et al. 2016) have been and are still being investigated. In sum, human cognition in manual assembly and in instructional design has been a widespread topic of interest (see, e.g., Stork and Schubö [2010]; Agrawala et al. [2003]; Heiser et al. [2004]). However, as relevant as these accounts are, there are three crucial drawbacks of procedural instructions, which prompt the creation of a novel alternative.

Firstly, operators often do not use instructions, but instead rely on their own experience, or that of other operators (Johansson et al. 2017b). Indeed, in some case, more than $60 \%$ of all tasks are performed based solely on own experience (Fast-Berglund et al. 2013). Possible reasons for this are given by Wieringa, Moore, and Barnes (1998) and referred to by Eiriksdottir and Catrambone (2011, p. 753): "They are inaccurate, out of date, confusing, unnecessary, too authoritative, difficult to understand or difficult to use, or treat the user as a child." Moreover, research on naturalistic decision making (NDM) and the recognition primed decision model (RPD) (see Klein [2008] for a review) has shown that people, when faced with complex situations, mostly rely on their intuition and experience instead of using analytical methods (Vera et al. 2014). Moreover, a different study showed that only 56\% of interviewed operators tend to trust assembly instructions, and that there is a clear mismatch between the way information is provided and the way it is actually used (Johansson et al. 2017b). Hence, much of the information in 
the assembly instructions is rarely used by operators, or regarded as important (Johansson et al. 2017a). As a result, operators find it sometimes to troublesome to seek for the information when the actions to take are believed to be clear. There is often a suboptimal trade-off between information-seeking costs and the utility of information (Fu and Gray 2006). When making this trade-off, many operators rely on their own experience first, and try to solve the assembly by merely looking at the components to be assembled constructing their own mental model of the assembly. As stated by Carroll (1990, p. 74): "People are always already trying things out, thinking things through, trying to relate what they already know to what is going on, recovering from errors. In a word, they are already too busy learning to make much use of the instruction."

Secondly, instructions influence operator cognition. When using external instructions (i.e., objects that are not part of the product itself, such as paper, screen or projected instructions), the need to memorise the explanatory information and integrate it with the physical information present in the components and subassemblies themselves, results in extra cognitive load. This effect, which is caused by divided attention and mental integration, is called the splitattention effect (Sweller et al. 1998). Hence, in situations where mental integration is needed to understand two or more information sources, physically integrated information can help avoid split attention and therefore reduce cognitive load (Chandler and Sweller 1991, 1992, 1996; Ginns 2006). Technologies such as augmented reality can offer new possibilities to tackle this problem of split attention (Huff et al. 2012). This is supported by the work of Re et al. (2016), in which better performance and lower cognitive load in operators in production were reported when the latter were supported by augmented reality. Nevertheless, these instructions can also cause frustration (through a negative coping appraisal, see McGrath [1976] and Matthews [2002]), and higher cognitive load when the information is redundant for the operator at that time in the process (Sweller et al. 1998; Kalyuga et al. 1998, 2004). Moreover, results indicate that avoiding redundant and non-task-relevant information, combined with offering information that corresponds to the cognitive task, also improves problem-solving handling (Dadashi et al. 2017). Suboptimal cognitive load can cause errors, unnecessary time spent on execution, performance degradation and reduced attention (Young et al. 2015). We refer to Young (2015) for a review and to Van Acker et al. (2018) for a critical concept analysis and generic framework on cognitive load (in these papers coined as mental workload).

Finally, procedural instructions can also inflict negative short-term and long-term effects on the motivation and mental wellbeing of the operator. A widely supported motivation theory in psychology, i.e. Self-Determination Theory (SDT) (Ryan and Deci 2000), postulates that the promotion or frustration of the three basic psychological needs (autonomy, competence and relatedness) is strongly correlated with self-motivation and mental well-being. Employees experience job autonomy when they have the feeling that the result of their work was accomplished by personal effort and control (Whittington et al. 2017). Following procedural instructions can have negative effects on their perceived autonomy, because the operator is forced to follow the instruction in the exact sequence that was planned by the work planners. It is also possible that, for a substantial group of operators, procedural instructions have a negative influence on perceived autonomy since they leave no, or at best only limited opportunities for the operator to bring his or her own interpretation to the product or the process. Nevertheless, in product assembly, many different assembly paths leading to the same end-product are possible and equivalent. Operators capable of handling difficult and unique assemblies are of great value for companies and keeping them motivated is therefore of great value.

In sum, these three crucial drawbacks make research on how to minimise the use of these procedural instructions very relevant. Moreover, as discussed above, in complex situations, people naturally act and react on the basis of intuition and prior experience. Furthermore, in complex assembly, tasks are intuitive, i.e., according to Mattsson et al (2018, p.19): “... gathering information, recognising elements in a situation and comprehending the situation (more or less aware and / or automatic)", and should be supported (Mattsson and Fast-Berglund 2016). Furthermore, empowering operators by allowing them to make decisions with respect to certain tasks within a complex environment was discussed by Mattsson et al. (2014) as a possible way to manage complexity. These insights also provide additional arguments to investigate other ways of supporting operators during assembly.

\subsection{Product design and the assembly context}

In current-day contexts of assembly, object-centred approaches are often favoured over operator centred approaches. At first sight, this seems to make sense. After all, in an industrial assembly context components are primarily 
designed to be assembled into a final product. Design for manufacturing and assembly (DFMA) is one example of an object centred design approach in which the assembly itself is analysed and adapted. DFMA allows designers and production planners to estimate assembly and production costs at an early stage (Boothroyd 1994). Operator cognition is not a key element in DFMA. However, both cognitive overload and underload can lead to performance degradation, attentional lapses, etc. (Wilson and Corlett 1995). Eventually, this can lead to mistakes, loss of productivity and even safety issues. Hence, the motivation of the operator is also important for companies, since there is a strong correlation between job satisfaction and performance (Judge et al. 2002) and because it avoids costs linked to absenteeism and staff turnover (see, Mowday, Porter, and Steers [2013] on the processes that link employees to work organizations). The new framework that we coin as Design For Assembly Meaning (DFAM) could complement DFMA by also taking cognitive aspects of the operator into the design process. This could in fact improve cognitive load, performance, task enjoyment and work motivation.

Product design plays an important role in how the assembly process is experienced by the operator. Operators interpret and give meaning to the components and subassemblies they encounter. Hence, if designers would design these components and subassemblies in function of their meaningful interpretation by the operator, the assembly process itself could be facilitated. At first sight, giving operators the opportunity to explore seems to conflict with many quality assurance strategies (e.g., where quality in production and assembly is assured by following strict procedural instructions). Nevertheless, an assembly 4.0 context in which the assembly process is monitored, errors are pointed out and information is offered to correct could open up possibilities to increase the autonomy of the operator in combination with products designed for intuitive assembly.

\subsection{Design for meaning in the context of use}

With respect to design for meaning in product design, many models and theories state either that the physicality of the product drives its perception, or that cognitive processes bring about the perceptual, subjective qualities of the product (Kapkin 2015). According to Kapkin (2015), these models have mostly focused on Affordance Theory (Gibson, 1979), Product Semantics (Krippendorff and Butter 1984) and on the Product Emotion model (Desmet and Hekkert 2002). However, the Product Emotion model focuses more on the perception of consumer products. Hence, Affordance Theory and Product Semantics are the most interesting theories for the purpose of this paper. However, there are still some preliminary questions we need to answer first: what is meaning, how can we define it, and is it really the designer who determines the meaning of a product?

Designers intend products to be experienced in a certain way and try to design their product accordingly. The way in which the intention of the designer relates to the interpretation of the product by the user has been described as a process of communication. In design literature, many models representing design as communication can be found (see Crilly, Maier, and Clarkson [2008] for a review). Nevertheless, many of them actually stem from one original model: of the general communication system proposed by Shannon and Weaver (1949). In this model, a message is produced by a source, encoded by a transmitter into a signal and then transmitted across a medium (prone to potential noise) before being decoded by a receiver into a message, which then arrives at its destination. However, according to Krippendorff and Butter (1993) meanings cannot be placed into products nor attached to them. As a result, designers cannot force users to use products in the way they intended them to (Krippendorff and Butter 1993). In fact, meanings are not designed but created by users themselves during their interaction with the product (Krippendorff 1989), within a given context (Siu 2003). Furthermore, interpretation in a user context can also generate alternative ideas on the use of the object (Redström and Grauers 2006). As a result, meanings are often hard to grasp or define. However, if the determination of a product's meaning is up to the user, what then is the task or responsibility of the designer exactly? According to Krippendorff and Butter (1993), designers should create interfaces that afford users all appropriate cognitive models and discourage them from trying out harmful ones. In order to understand this point, we first need to discuss affordances and product semantics.

The first author to introduce affordances into design research was Norman in his book: The Psychology Of Every Day Things. According to Norman (1988, p 9), an affordance refers to: "the perceived and actual properties of the thing, primarily those fundamental properties that determine just how the thing could possibly be used.". Affordances can be either positive (beneficial) or negative (disadvantageous), and as a result can be desired or undesired. This polarity of affordance (originating from Gibson [1979]) is a crucial property for designers. As shown 
by You et al. (2007), affordances highlight possible actions but fail to inform the user about their consequences. This can encourage the user to engage in trial and error behaviour, resulting in inefficiency and disadvantageous situations. To reduce this kind of behaviour, designers can, according to You et al. (2007), either remove the undesired affordances or focus on product semantics to provide the information that helps predict the consequences of the actions beforehand. According to Krippendorff and Butter (1984), the concept of product semantics is to be understood as a set of meanings associated with product features such as forms, shapes, textures, etc. One example of this (originally used by Gros and cited by Vihma [1995], and Boess and Kanis [2008]), are the grooves of a handle that explain how to grasp it. In this sense, the grooves do more than just determine the look of the object: they also express its intended use. Affordances and product semantics will provide the cornerstones of our DFAM framework.

In the following sections, we will first explain how the DFAM framework is defined and how it is situated in relation to design for meaning and the assembly context. Subsequently, we will explain how insights, theories and concepts from design for meaning can be used in or adapted for DFAM (i.e., the overall view on design as a communication language, affordances and product semantics). In this respect, the link to assembly will always be made in light of the new DFAM framework.

\section{Defining and situating a framework for DFAM}

\subsection{Defining a framework}

To our best knowledge, there has been no (or at most only very limited) research from a product design perspective on how the use of procedural instructions can be reduced by designing components and subassemblies that have meaning for operators, in relation to tools, jigs, fixtures and the environment of assembly. Nevertheless, as mentioned above, existing theories on design for meaning can deliver valuable input for a new framework that considers meaning specifically in a context of manual assembly.

Let us start with providing a clear and direct definition of DFAM, i.e.,: "DFAM is a framework that offers designers insights to design products that support the assembler in constructing an appropriate mental model of the assembly process when interacting with components, subassemblies, tools, jigs, fixtures and the assembly environment." First of all design for meaning treats meaning on a product level and within a context of use, while DFAM considers meaning at the level of a connection, component or subassembly in relation to the assembly context with the specific goal to lower the number of instructions needed. Secondly, this definition also incorporates the central contributions of DFAM (i.e., operator centeredness, focusing on the construction of a mental model of the assembly process by the operator) compared to DFMA (which is object- centred and does not focus on the mental model of the assembly process as constructed by the operator). As said in the introduction of this paper, this new approach could potentially avoid all of the drawbacks of procedural instructions mentioned above. Firstly, operators always need to look at the components and interpret them in order to assemble them, regardless of whether or not they promote assembly meaning. Secondly, physical integration brings the information directly to the operator, who is not forced to divide his attention between the external procedural instruction (e.g., on screen, paper, ...) and the physical components or subassemblies. Thirdly, by avoiding step-by-step instructions, the perceived autonomy of the operator could be fostered, allowing the operator to discover, interpret and decide on how to continue the assembly, which could increase work motivation. In order to construct a framework based on these principles, insights were gathered through four phases of literature review and pilot studies [see, Parmentier et al. (2019) for more information on the pilot studies].

- Phase 1: literature review on different aspects that define the context (i.e., manual assembly, procedural instructions, industry 4.0, design for assembly and product design )

- Phase 2: literature review specifically focused on design for meaning and design as communication (i.e., design for meaning, design as communication, affordances and product semantics)

- Phase 3: Pilot study where students redesigned a product with a focus on meaning during assembly.

- Phase 4: Pilot study where students designed a product with a focus on meaning during assembly 
For our review of literature in Phases 1 and 2 , Google Scholar and Web of Science (Core collection) were used. We used keywords such as: "manual assembly", "product design", "design for assembly", "procedural instructions", "Industry 4.0", "design for meaning", "design as communication", "affordances", "product semantics" and combinations of these keywords. The first keywords address the context of DFAM while the last four keywords address design for meaning and design as communication. In addition to this literature review, pilot case studies were run in phases 3 and 4, in which products were redesigned and designed by undergraduate students in Industrial Design Engineering Technology with a focus on assembly meaning. The students were only shown examples from the book "the Psychology of Everyday Things" (Norman, 1988) illustrating the use of semantics and physical constraints. They did not receive additional information (affordances and product semantics were not explained) or a framework to design for meaning in an assembly context. These pilot case studies were run in order to gather insights on the solutions that were found "intuitively" to design for meaning in assembly, and to determine whether a framework could be of help to design or redesign the products with a focus on DFAM. Many of the products designed in these case studies had difficulties that prevented intuitive assembly and confirmed the need for a framework. Nevertheless, the results of these case studies illustrated how physical constraints can be used to alter affordances and how perceptual cues can be used to trigger the creation of meaning (i.e., product semantics or semantics of the environment). In the pilot case study (i.e., redesigning a product, phase 3 ), the use of spatial arrangements (e.g., spatial cueing and clustering of components, i.e. semantics of the environment) was also confirmed to be of interest in promoting the creation of meaning in an assembly context (this will be discussed later in this paper). We cannot say that the designer, when considering DFAM, integrates assembly instructions into the components of the product itself. It is more correct to state that the designer facilitates the required possibilities of action (i.e., affordances) by removing or adding physical constraints, and the perception of these affordances by changing the perceptual properties of connections, components and subassemblies and subsequently their associated meanings (i.e., product semantics). Hence, the framework intends to help the designer to first define necessary, useful, confusing or incorrect possibilities for action (affordances) and, secondly, to alter them or their perception when needed.

\subsection{Situating DFAM in an industry 4.0 manual assembly context}

A smart industry 4.0 information system (i.e., monitoring the process and alerting for errors combined with contextual and situational information that is readily available) offers a lot of possibilities to increase autonomy in combination with products designed for intuitive assembly. In Fig. 1, the proposed framework is situated in an industry 4.0 manual assembly context. The input (single arrows) and interactions (two-way arrows) between the different entities within this context are visualised. DFAM is shown as a focus from the designer on the construction of an appropriate mental model (for assembly) by the operator. This focus is translated through the design of connections, components and subassemblies (illustrated by the loop around the components, etc. in Fig.1) which stimulate the correct interpretation of the assembly by the operator. The interaction of the operator with the assembly is represented by means of a two-way arrow.

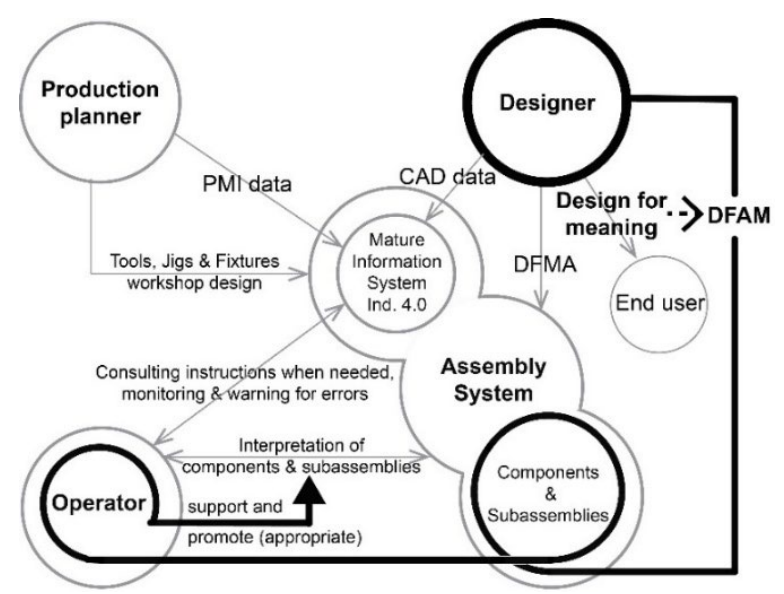

Fig. 1 Situating the DFAM framework and the input of design for meaning within an industry 4.0 assembly context. 
The input from design for meaning as well as other inputs (e.g., from the production planner and the designer) and interactions (e.g., the operator interacting with the assembly system and with the information system) are represented as well. During the design process, designers (designing the product, components, subassemblies, choosing materials, finishes, etc.) generate CAD (Computer Aided Design) data (e.g., 3D models of components and subassemblies). This CAD data is a representation of the product and is used in assembly 4.0 information systems. Designers also consider DFMA during the design of their product, which also has an impact on the assembly process and the system. The production planner (fine-tuning production, providing tools, jigs, fixtures, etc.) also enriches the available CAD data (part of intelligent assembly 4.0 information system) with more product and manufacturing information (PMI) data. Furthermore, designers can also add PMI data to their CAD model, but in Fig.1 this is considered as part of the CAD data input of the designer. Designers and production planners work concurrently on these CAD models and PMI data. Production planners also take the processes on the workplace into consideration and provide tools, jigs and fixtures to optimise the process. In a mature industry 4.0 information system, software algorithms could also analyse potential assembly sequences which all lead to successful assembly. This data could then be used to monitor the assembly sequence and alert the operator when an error occurs. This smart information and monitoring system could also help to discover dissonances (i.e., incoherencies or conflicts between knowledge, e.g., between knowledge of the designer and knowledge of the operator). Moreover, aside from discovering these dissonances, controlling them is equally important for the development of knowledge from situations that may occur (Vanderhaegen and Carsten 2017). Difficulties with components and subassemblies on both the physical or cognitive level could also be discovered, and again serve as input for the designers to optimise their designs.

\section{Design for meaning offering insights for DFAM}

As discussed in the introduction on design for meaning, when considering meaning in an assembly context, affordance theory and product semantics are the most interesting theories. These theories were reviewed together with the more general view of design as communication, and in this section, we link the resulting insights to an assembly context, constructing new insights that specifically apply to DFAM.

\subsection{Design as communication in DFAM}

Components and subassemblies mediating between the designer and the operator can be seen as a type of communication. As described in the introduction, many models of communication originate from the model proposed by Shannon and Weaver (1949). This model can also be applied to the communication process starting from the designer as the information source, promoting a message on how to assemble the designed product to the operator. In many companies, instructions are made by work planners or technical writers, not by the designer of the product. Making instructions is in many contexts often treated as a separate process (e.g., for software, Rettig [1991] and Knapheide [2000]). Hence, the communication process is in fact doubled, which lacks efficiency and increases the chance of misinterpretation (see Fig. 2 a). In Fig. 2 b an alternative is presented, again based on the model of Shannon and Weaver (1949), which uses the product (components and subassemblies) as a medium to promote meaning for the operator. Furthermore, it also provides, as a backup for the operator, 3D CAD models containing the complete product definition, enriched with PMI data (i.e., MBD, model based definition) produced by designers in cooperation with work planners. Information of designers and work planners is integrated into one information system where it can be used to offer tailored information, or as a way to be alerted for errors (as illustrated in Fig.1 and Fig.2). This situation is along the lines of the assembly 4.0 scenario presented by Erol et al. (2016). 

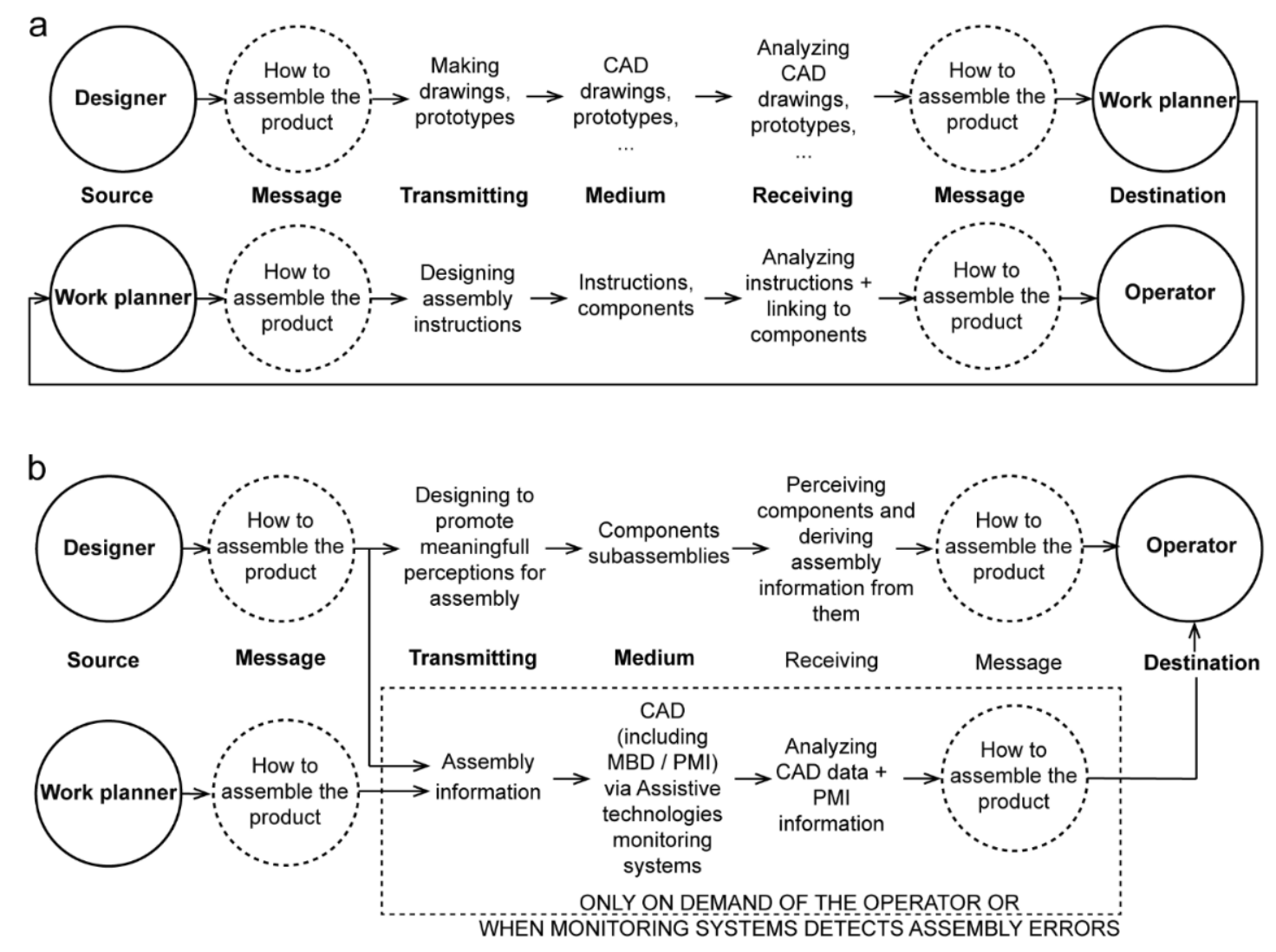

Fig. 2 Communication processes in assembly from designer to operator, based on the model of Shannon and Weaver (1949): (a) Designer - Work planner- Operator model (applied in many companies) (b) Designer - Operator Model: (model showing the potential of design as communication in an assembly 4.0 setting)

In this designer - operator model (b), the components and subassemblies are represented as media, mediating directly between designer and operator, thereby bypassing the process of translation into explicit procedural instructions. Eventually, a double communication process such as in Fig. 2a is avoided. This results in a reduced number of steps, which opens up possibilities to increase the autonomy of the operator and the promotion of assembly meaning within an assistive, yet controlled, environment. As mentioned before, this setup could lead to positive effects with respect to cognitive load and work motivation.

Fig. 3 illustrates by means of an example how assembly meaning is constructed by the operator through the interaction with multiple components, subassemblies and the assembly environment itself (e.g., tools, jigs, fixtures, etc.). The designer is trying to promote a desired meaning while bearing the operator in mind, and the operator is also considering the designers' intentions while interacting with these components and subassemblies. During these interactions, the operator receives feedback and eventually constructs assembly meaning. This model is based on the interpersonal part of the integrated communication-based model of design that was proposed by Crilly, Maier, and Clarkson (2008). In this part of the model a product mediates between designer intentions and consumer interpretations, depicting issues such as mutual awareness, artefact variation and reflective representation. Fig. 3 incorporates these issues in an assembly context in which components and subassemblies mediate between designers and operators. The interactions of the operator, who iteratively interacts with the components and receives feedback from these interactions, which lead to the construction of assembly meaning and eventually result in assembly actions, are also illustrated in Fig. 3. 


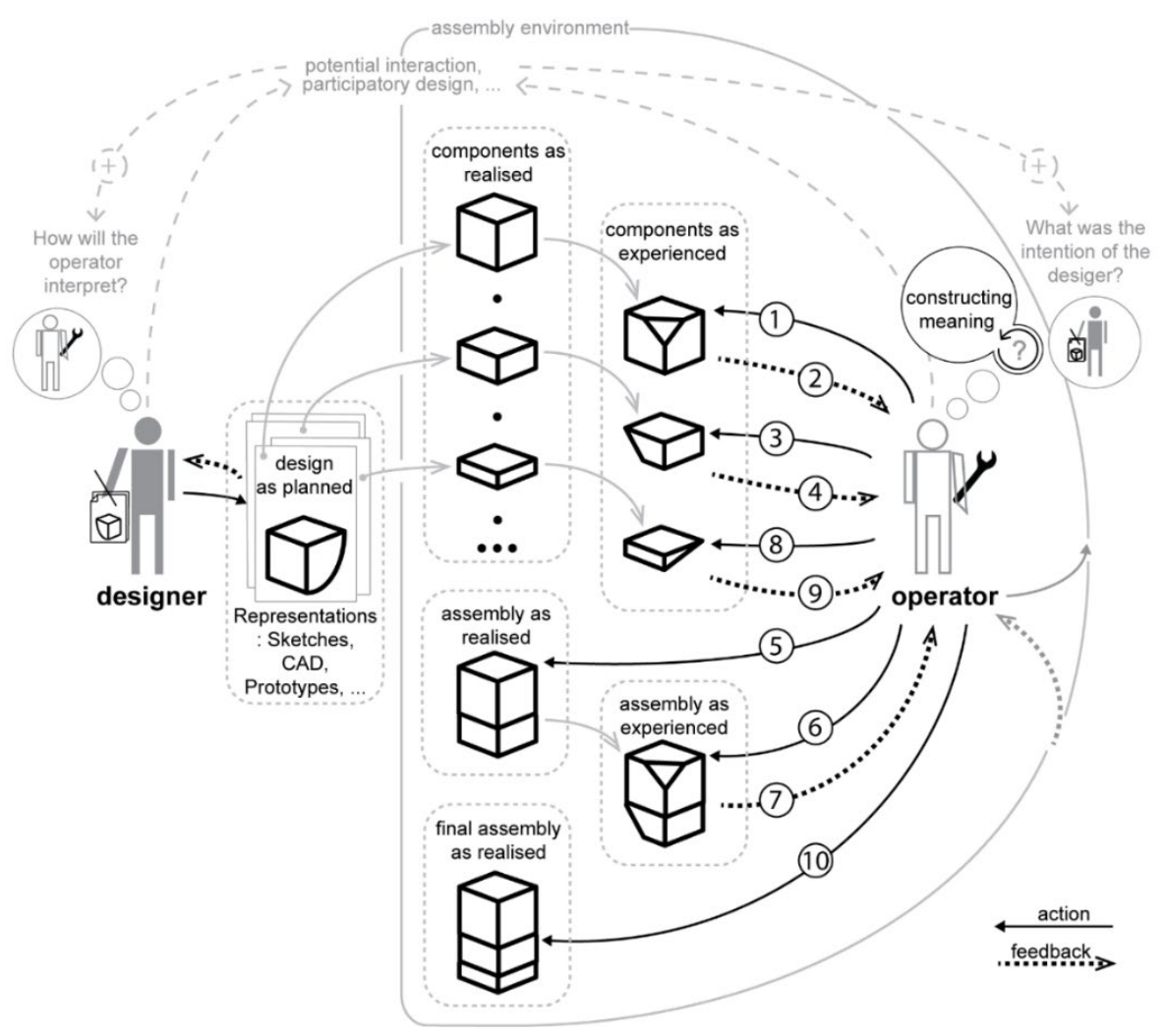

Fig. 3 An example of mediating components and subassemblies and the construction of assembly meaning, based on the interpersonal part of the communication based model of design proposed by Crilly, Maier, and Clarkson (2008).

When we look at Fig. 3 in somewhat more detail, we can see that the operator's perception can differ from what the designers intended. Firstly components and assemblies can potentially differ from the designers intention due to intended or uninteded design changes linked to production of the components or to changes during assembly. Secondly, the operator experiences the components in a certain way, which again can potentially differ from the designer's intentions. Hence, a desired interpretation cannot be garanteed to be realised. Potential interaction and participatory design approaches between designer and operator can help (illustrated in Fig. 3 with a + mark) relate interpretation to intention and should be encouraged when possible. Assembly actions, resulting from the operator who iteratively constructs assembly meaning, are also illustrated. Once the operator interacts with the components or subassemblies (1)(3), he receives feedback (2)(4), discovers affordances and constructs assembly meaning, which eventually renders assembly possible (5). After this first assembly of two or more components, the operator interacts with the newly formed assembly (6) and the remaining components (8). During these interations, the operator receives feedback (7)(9), constructs new assembly meaning from these interactions, and is eventually able to assemble new components or subassemblies together with the existing assembly (10). The presented sequence is only one example; different sequences are possible. The iterative proces of interacting with components, subassemblies, the environment and of receiving feedback by doing so, results in affordance perception, construction of assembly meaning and, eventually in actions that push the assembly process forward. Hence, assembly meaning cannot be constructed during interaction with one component or subassembly, but only after interacting with multiple components or subassemblies.

To summarise, we have now looked into the interactions of the operator that construct meaning for assembly. But how can designers then promote the meanings they advocate, and how can they avoid undesired ones? As Kroes (2002, p. 298) stated: "... since the function is not an intrinsic property of the artefact, it is not clear what it is in the 'artefact itself' that is the source for the communication of its function". Aside from its function within the assembly or product, the function of a component before assembly is to be assembled together with other components into a subassembly or final assembly. The act of assembling itself is not an intrinsic property of the component or subassembly. Nevertheless, as operators interact with the components and subassemblies, they derive possible 
actions or affordances from these interactions. These affordances are pivotal for the designer, since actions can be facilitated or avoided by means of the design.

\subsection{Affordances in DFAM}

Desired affordances need to be facilitated physically, and undesired actions need to be discouraged. Interestingly, when Norman addressed affordances, he actually meant: "perceived affordances" (Norman 1999). After all, perceiving affordances is of crucial importance in assembly. When a desired affordance (e.g., the action possibility of connecting two components) cannot be perceived, correct assembly becomes precarious. In this section, we will describe different types, combinations, groups, etc. of affordances and how they play a role in an assembly context.

\subsubsection{Types of affordances and how to alter them}

Gaver (1991) made a distinction between affordances themselves and the information that is available about them, which resulted in four different types (i.e., perceptible affordances, hidden affordances, false affordances and correct rejections). False affordances (the possibility for action is perceptible, but is non-existent) and correct rejections (there is no possibility for action and it is also perceived as non-existent, i.e. it is correctly rejected) are not real affordances in contrast to perceptible affordances (perceptible and existing action possibility) and hidden affordances (a non-perceptible but existing action possibility), they do not convey real possibilities for action. False and perceptible affordances are both perceptible: they can trigger the operator to act. Correct rejections and hidden affordances, on the other hand, are not. As a result, false affordances encourage an operator to engage in an impossible action, while hidden affordances do not encourage the operator to act upon a real action possibility.

In Fig. 4, we adapted the framework offered by Gaver (1991) by adding possible pathways (illustrated by arrows) to alter affordances or their perception. In order to change the perception of affordances, perceptual cues promoting the construction of meaning (i.e., product semantics or semantics of the environment) are added or removed. In order to transform affordances into non-affordances and vice versa, physical constraints are added or removed, i.e., in line with the manipulation of physical properties as suggested by You et al. (2007). The positivity or negativity of an affordance (i.e., polarity of affordance according to Gibson [1979]) was also integrated in Fig. 4 (i.e., by means of different types of lines). The preferred pathway depends on whether the affordance itself is desired or undesired. A perceptible affordance is preferred for desired affordances, a correct rejection is preferred for undesired affordances. Designers should strive to attain one of these two statuses depending on the polarity.

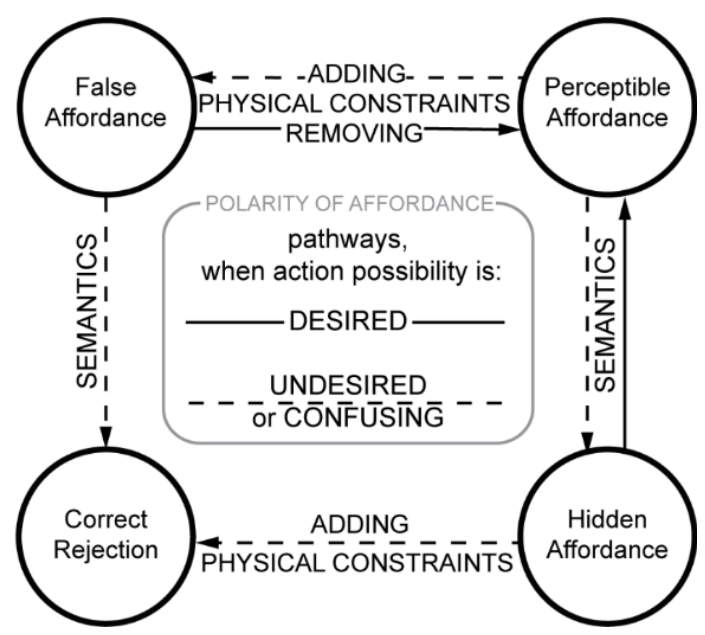

Fig. 4 Potential pathways, depending on the polarity of the affordance, to change the type of affordance. (Adapted from Gaver, 1991) 
However, achieving these statuses is not always possible (e.g., because the solutions needed to achieve them conflict with other affordances). A perceptible affordance can be undesired if it is harmful (e.g., where perceptual cues encourage to remove a component that shields against a dangerous substance) or useless to the operator at a given time and diverts attention from a different affordance (e.g., where perceptual cues encourage to turn one component when another component should be turned at that time). Ideally, the designer should transform it into a correct rejection, or at least into a false affordance (i.e., the action becomes impossible) when the action is harmful (e.g., make it impossible to remove a component that shields against a dangerous substance by adding constraints), or into a hidden affordance (i.e., imperceptible) when it is merely confusing (e.g., remove the perceptual cue that distracts from turning the right component). In contrast, hidden affordances could be desired if the operator would notice them (e.g., a part of a snap connection which, due to its shape, is not perceived as part of a snap connection). When the affordance itself is desired (e.g., possibility to connect), designers should transform hidden affordances into perceived affordances (e.g., change the part of a the snap connection so that it looks flexible and deformable). Transforming hidden affordances into correct rejections could be desired if the hidden affordance is harmful or confusing when accidently acted upon (e.g., accidently unlocking a snap connection by pushing a casing onto a particular place). This can be resolved by adding physical constraints that make unlocking only possible when using specific tools, making accidently unlocking the snap connection impossible. Changing correct rejections is irrelevant because they are correctly rejected anyway (they are also hidden and non-existent). False affordances should become correct rejections when they are confusing to the operator (e.g., when the user is triggered to stack a component on another component when this is not possible, remove the perceptual cues that triggered the action) or should become perceptible affordances when the action they trigger is desired (e.g., when stacking is desired, make stacking possible by removing the constraints that prevent the stacking). Designing components and subassemblies in such a way that desired affordances are possible and perceptible, and undesired affordances are not, is a first approach to designing products that are easier and safer to assemble. Subsequently, if a useful or needed affordance is hidden in a design, the designer should redesign it to make it perceivable. If, on the other hand, a design contains undesired affordances or false affordances that could confuse the operator or even harm her or the product, the designer should redesign and eliminate these affordances.

In a context of assembly, it seems insufficient to regard affordances as nothing more than possibilities for action by operators. If a designer would only regard affordances as possibilities for action in relation to an operator, successful assembly would become precarious because relations between components, subassemblies, tools, jigs, etc. remain unnoticed. It is not because two components allow grasping, orienting and positioning, that they can be joined together. Two components can only be joined if, in addition to the affordances mentioned above, their geometries allow them to be joined as well. Maier and Fadel (2009) generalised user and artefact as two interacting systems. They also described these inter-objects or artefact-artefact affordances (AAA's) and artefact-user affordances (AUA's) in a designer-artefact-user system in which product features define both affordance types. Affordances that afford handling are clearly AUA's. Affordances that afford actions towards other components (e.g., sliding, stacking, etc.) can be considered AAA's because the possibility for action only exists when the link between the two components (artefacts) is established.

\subsubsection{Combinations, groups and sequence of affordances.}

In general, the action possibility of assembly itself can be seen as the most important possibility for action or affordance of a component or subassembly within a context of manual assembly. As illustrated before, more than one affordance is needed to afford manual assembly. For example: two components could afford manual assembly but, in order to do so, at least one component must afford grasping, orienting, positioning (AUA) and fixating with the other component or subassembly (AAA). Designers can design components in such a way that a component affords grasping, orienting and positioning, but only affords connecting with one specific component to form a snap connection. To afford such a connection, at least one of the two components must have a flexible part that fits into the other component, so that connecting becomes possible (AAA). However, it will be impossible for the operator to manually snap the two components together if the force needed to deform the snap exceeds the operator's capability (the required AUA is non existing). This example makes it clear that manual assembly consists of various types of affordance, and that affordances needed nor the operator himself may not be overlooked. If the designer overestimates the operator's capabilities on the perceptual or on the physical level, it will be impossible for the operator to take action, and affordances become inexistent. The example of a snap connection also shows that not all 
affordances are always perceivable from the very beginning (e.g., the component must first be manipulated in order to discover its flexibility and use in a snap connection). This is in line with the findings in Gaver (1991). According to Gaver, acting upon a perceptible affordance can lead to information that indicates a new affordance. Gaver indicated that complex actions consist of groups of affordances, which are sequential in time or nested in space. Manual assembly can be considered a complex action in which multiple affordances, both AAA and AUA, follow each other in a sequential and nested structure.

Gaver also showed that affordances should not be passively perceived, but rather explored in order to discover new affordances. During assembly, components are explored: they are grasped, touched, turned, positioned and finally fixed in- or onto another component or subassembly. During this exploration, new affordances of components and subassemblies are discovered. The result is a process that guides the operator during assembly (this was also illustrated in Fig. 3). Discovering assembly affordances by interacting with components and subassemblies can be very intuitive, which is not the case when following procedural instructions. When users explore affordances, they engage in a series of actions that generate perceptual information. Hence, designers should design for these actions and their associated perceptual information (Stoffregen and Mantel 2015). In order to make perceptual information on affordances more controllable, Lu and Cheng (2013) presented the concept of perceptual threshold of affordance, in which perceptual cues can raise or lower the affordance threshold and hide or highlight affordances. By changing the perceptual state of an affordance, its threshold can be reduced, while the threshold of another affordance can be increased as a result of the competitiveness of affordance perception (Lu and Cheng 2013). For example: embossing and adding a contrasting colour to one fixation point of a component can highlight that particular fixation point, but also hide other points which do not have a contrasting colour or an embossed shape. In this example, product features and their associated product semantic (e.g., meaning this is a fixation point) are used to change the perception of affordance, as illustrated in Fig. 4 by means of semantic arrows, by lowering or augmenting their perceptual threshold. However, dominant perceptual cues linked to component features can become invisible after this specific component has been assembled, which opens up possibilities for other perceptual cues. Designers can use this to support assembly sequence perception.

\subsubsection{Additional affordances in an assembly context}

Components and subassemblies are not the only entities which have affordances. Tools, jigs, fixtures and assembly environments do so as well. They can afford totally different actions than components and subassemblies. How tools are used exactly on a cognitive level is the subject of ongoing research (see e.g., Baber et al. [2014)] on tool use as distributed cognition and Osiurak [2016] on comparing manipulation-based approaches with reasoning-based approaches). Nevertheless, in an assembly context, tools must afford certain operations for the operator that would be impossible without the tool. Affordances of tools can vary greatly. Some tools can help the operator work more precisely, and help her grasp or position components, while others can enlarge movements, force, etc. Jigs and fixtures can afford or even force correct positioning of the components with regard to one another before final fixation. The environment can support the assembly by displaying all the components and arranging them according to their function. It can afford grasping of the components by placing them in sight and within reach of the operator. Spatial arrangement and clever placements of components and subassemblies can also influence perception; they can hide affordances or draw attention to them by highlighting what is possible (Kirsh 1995). Kirsh (1995, p. 51) stated the following on the use of space in assembly: "If I can arrange items to display the sequence they are are [sic] to be used in, then I don't have to remember that order, or figure it out, or consult the manual, as long as I know how to read the information off the local properties of the world.". Kirsh (1995) showed how space can be used in an assembly context to cluster and order components or subassemblies so that the construction of the subassembly and the assembly sequence becomes clear, eventually simplifying choice and perception. Brolin et al. (2017) gave an example, i.e. the structured kitting of components, of how the assembly environment can provide information on the assembly. This kitting eventually decreased the need to search and interpret other information. This is interesting in an assembly context, where there is a selection problem first and a placement problem afterwards. When applying DFAM, links between different components and subassemblies can be made, and even indications where to position a component within an assembly are possible on a component and subassembly level (we discuss this in the section about product semantics). However, indicating the sequence in which components are to be assembled, or indicating which subassemblies need to be assembled first, is difficult to design on this level. This is of course not always necessary because there are multiple ways to assemble a product. Nevertheless, in some assemblies, assembly 
sequences can be important. For these kind of assemblies, arrangements in space and time can offer a solution. They would still let the operator interpret the presented components and limit the need for procedural instructions. Using spatial arrangements to support the construction of meaning for assembly by hiding or highlighting affordances is a semantic undertaking. Furthermore, in this example, semantics is also used to render affordances perceivable and understandable.

\subsubsection{Identifying affordances for DFAM}

As mentioned above, affordances only exist in virtue of the relation between two interacting systems, as generalised by Maier and Fadel (2009). As a result, in a manual assembly context, it is absolutely necessary to take both the operator and the components and subassemblies into account. Cormier and Olewnik (2014) defined several prompt questions in order to identify users, artefacts and affordances in the early stages of design. Operators, interacting artefacts and affordances, should also be identified by designers in order to facilitate the required AUA's (artefactuser affordances) and AAA's (artefact-artefact affordances). Nevertheless, aside from these desired affordances, designers should also identify what the design should not afford in order to avoid negative, undesired affordances (Maier and Fadel 2009). In Table 1, we have formulated specific questions for a manual assembly context in order to trigger the designer to identify operators, artefacts, desired and undesired affordances. Identifying and designing product features that provide the necessary affordances is a first step in facilitating the assembly process. However, affordances, especially AUA's are not very useful if they are not perceived and interpreted by the operator, which brings us to the following section.

Table 1 Questions to identify operators, artefacts and affordances within a manual assembly context.

\begin{tabular}{|c|l|}
\hline & \multicolumn{1}{|c|}{ IDENTIFYING OPERATORS (O) } \\
\hline O & Are multiple operators involved in the assembly or subassembly? \\
\hline O & Who positions the components in the assembly environment? \\
\hline O & Who selects the components for the assembly task? \\
\hline O & Who assembles the subassembly(-ies)? \\
\hline O & To whom is the subassembly transferred when it is completed? \\
\hline & \multicolumn{1}{|c|}{ IDENTIFYING ARTEFACTS (AR) } \\
\hline AR & $\begin{array}{l}\text { Which component(s) or subassembly(-ies) need to interact with the current component or } \\
\text { subassembly? }\end{array}$ \\
\hline AR & Which fasteners or adhesives are needed to fixate this component? \\
\hline AR & Which tools interact with the current component or subassembly? \\
\hline AR & Which jigs and fixtures are used by the current component or subassembly? \\
\hline & \multicolumn{1}{c|}{ IDENTIFYING AFFORDANCES (AF) } \\
\hline AF & $\begin{array}{l}\text { Which manipulations for positioning are needed or should be avoided on this component or } \\
\text { subassembly? }\end{array}$ \\
\hline AF & $\begin{array}{l}\text { Which manipulations should or should not be performed with tools on this component or } \\
\text { subassembly? }\end{array}$ \\
\hline AF & Does the component allow the positioning and application of the desired tools? \\
\hline AF & $\begin{array}{l}\text { Which manipulations are needed or should be avoided when repositioning subassemblies or } \\
\text { intermediate results during assembly? }\end{array}$ \\
\hline AF & $\begin{array}{l}\text { Which connection types are desired or undesired with other components, subassemblies, jigs } \\
\text { and fixtures? }\end{array}$ \\
\hline AF & Is the component still accessible, by hand, by the use of tools, ... after assembly? \\
\hline AF & What is needed in addition to components and tools to complete the assembly? \\
\hline
\end{tabular}




\subsection{Semantics in DFAM}

Making desired affordances perceptible and hiding undesired affordances are both matters of semantics. Both product semantics associated with component features or subassemblies and the semantics of the assembly environment (e.g., meanings associated with spatial arrangement, clustering of components, presence or absence of tools, jigs and fixtures) can highlight or hide affordances. How product semantics impact the affordance of assembly or even disassembly (partial disassembly [e.g., on subassemblies supplied by others] is very common during an assembly process) can be illustrated by means of the example of a cap. The shape or anti-slip marks on a cap can indicate whether to pull or turn it. However, without any marks, the affordance of turning or pulling the cap is still there. The difference is that it is just not clear to the user whether to turn or pull, or sometimes even that the thing is a cap in the first place. By choosing, for example, a different colour, one can see that it is a separate object. A different colour may have a meaning (i.e., product semantic) and does not change the affordance of pulling or turning the cap, nor does it provide information on whether the user should pull or turn. This example illustrates that, also on a component level, different product semantics are sometimes associated with different product features, and that combining them can be useful to highlight the desired affordance. In an assembly context, product semantics should be concerned with how certain features of components or subassemblies can make the operator link the components to each other, understand their position in the assembly or trigger the operator to engage in exploratory actions to discover necessary affordances. Perception and understanding of how to join, where to position and how to proceed are key aspects during assembly.

\subsubsection{Linking components to each other}

If we go back to the grooves in a handle, the number of grooves and the shape of the grooves are linked to the fingers of a hand, indicating where those fingers should be placed on the handle. In other words, they link two entities, highlighting their shared connection. In the example of the grooves, this is achieved by mapping the contact surface of the fingers onto the handle by changing its shape. This technique is also feasible in assembly situations where the contact surface of one component can be marked onto the other component. Multiple solutions can be found to map, project or mark contact surfaces of components onto each other, depending on the possible shapes, materials and production techniques. For example, mapping can be done by changing the shape of the components (e.g. by embossing in the case of the handle), by adding the texture of one component onto the contact surface of the other component, or by adding colour or labels to both contact surfaces. Depending on the material, function and lot size, various production techniques can be used. Fig. 5 illustrates the technique of adding colour. It shows a bookcase that was produced out of plate material and assembled by using wood connections. To facilitate assembly, colours were added to the connections, linking the contact surfaces of the components to one another in such a way that the colours match inside the wood connection when assembled. After the bookcase is assembled, the colours are invisible.

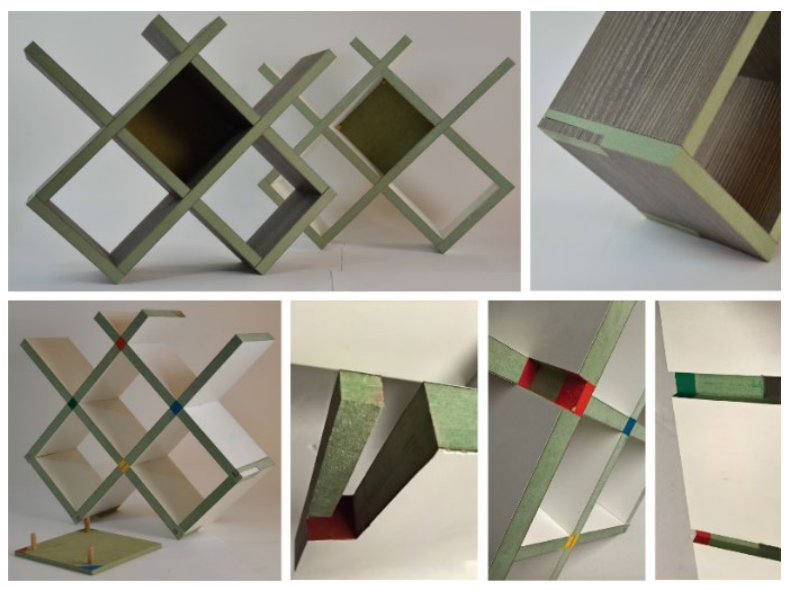

Fig. 5 Bookcase / DVD rack, designed in Phase 3 ( pilot case-study), with colour added on the contact surfaces of components, indicating their shared connection 
This bookcase was designed by three undergraduate students in Industrial Engineering during a prior pilot-study (i.e. Phase 3). The presented example can be linked to the action feedback loops illustrated earlier in Fig. 3, where meaning is constructed after interacting with components and subassemblies. Interaction with one shelf (e.g., looking at the shelf and the connection side of the shelf, i.e., action number 1 in Fig. 3) gives feedback (i.e., number 2 in Fig. 3 , e.g. visual feedback) and meaning is constructed by the operator on what the connection with another component could or should be like. When interacting with (e.g., looking at) the matching component (i.e., number 3 in Fig. 3), the operator again receives feedback (e.g., on the shape of the connection and the colour that was added, i.e., number 4 in Fig. 3) and constructs assembly meaning (i.e., linking the components, their position and their fixation to oneanother by e.g., linking the shapes and colours of the connections to one-another).

\subsubsection{Positioning components within the assembly}

In addition to how components need to be joined, the orientation and position of a component in relation to other components or subassemblies can support the operator's understanding of the assembly process. As previously mentioned, spatial arrangements and spatial cueing can be used to indicate how components and subassemblies need to be positioned. This solution is semantically related to the context of the assembly rather than to the components or subassemblies themselves. Icons, symbols, ... linked to conventions and product features can highlight how to orient and position components within the assembly. Furthermore, product metaphors applied on a component or subassembly level can be used to indicate their position. Hekkert and Cila (2015, p. 199) defined a product metaphor as: " $\ldots$ any kind of product whose design intentionally references the physical properties (e.g., form, sound, movement, smell, and so on) of another entity for specific, expressive purposes.". A product metaphor applied on a component level can help orient and position that component within the assembly. For example, if a component refers to some physical properties of a foot, one can understand that it should be placed at the bottom of the assembly, with the side that looks like a foot sole pointing to the floor, regardless of the other components within that assembly.

\subsubsection{Using product semantics for exploratory actions}

As discussed above, some necessary affordances can only be discovered after having explored the component or subassembly (i.e., the actions illustrated in Fig. 3). For these types of affordances, perceptual cues are needed to trigger the necessary explorative actions. In some cases, actions (e.g., deforming, bending, etc.) can only be afforded when a specific tool (e.g., a plier) is placed and used on a specific location of a component. In this case, the designer should design the component in such a way that the operator is prompted to use that tool on that specific location to discover the affordance offered by the tool at that location. Depending on the material and production technique, this can be achieved by, for example, changing the shape or by adding colours, prints, etc. If this is possible within a certain company, conventions related to tools (such as colour codes or symbols) could be added to the components to indicate which tool should be used where. These examples show that visual cues can have meaning to operators and can trigger the actions that reveal the hidden affordance. Nevertheless, components and subassemblies can also be explored by other means that designers can use and design for. Different types of connections (e.g., snap connections, gluing, sliding, ...) can be highlighted by tactile attributes such as compressibility, adhesiveness, smoothness, etc. of the surfaces. Audible cues, (or the absence of audible cues) can trigger operators to engage in exploratory actions (e.g., the absence of a snapping sound triggers the operator to push the components further onto or into one-another, while hearing a snapping sound helps us understand that the components are fully joined. It is clear that a variety of product features can address different senses and promote different meanings (i.e., product semantics). They can highlight affordances directly, or trigger exploratory actions that make desired affordances perceptible. 


\section{Discussion and future research}

Operator centred approaches, do not necessarily conflict with efficient and qualitative assembly. Moreover, neglecting the operator can have detrimental effects on performance, task enjoyment and work motivation. If they are supported (e.g., by smart monitoring and information systems), operators could be given much more autonomy during the assembly process. However, products supporting the construction of an appropriate mental model (i.e., assembly meaning) by the operator are needed here. As a first step towards a DFAM framework, we reviewed theories relevant for design for meaning (e.g., design as communication, affordance theory and product semantics), ran some pilot case studies and connected the acquired insights to an assembly context, constructing new insights specifically on DFAM. These newly acquired insights, as well as other relevant insights, are presented in Table 2, which offers input that can be taken into account in future research on DFAM.

DFAM starts with providing at least appropriate affordances and avoiding harmful ones. Identification of the affordances involved is a very important step. Specific prompt questions to identify the operators, the artefacts and the affordances are presented in Table 1 . These prompt questions can help the designer consider the components and subassemblies more systematically. Affordances can be nested in space, be sequential in time, and can sometimes only be discovered through exploration by the operator (Gaver 1991). Hence, it is also important to consider how identified affordances are described. Describing an affordance as, for example, the possibility of assembly, lacks depth, since manual assembly is a complex action with several sequential and nested affordances (both AAA's and AUA's, i.e., according to Maier and Fadel [2009]). When describing the affordance only at this level, some crucial affordances are not taken into account. As a result, it is important to be aware of the level on which the affordance is described and assess whether affordances on other levels are relevant too. Affordances in assembly can be described on a level of manipulation (e.g., rotating), effect (e.g., aligning) or use (e.g., fixating). These three levels are also three of the four levels described by Pols (2012) in his description of the affordances model.

Depending on the type of affordance as categorized by Gaver (1991) and the polarity of affordances (Gibson 1979), various pathways to alter affordances or their perception were discussed. Physical constraints can be removed to facilitate a desired action or added to make an undesired action impossible. Nevertheless, the designer has to be aware of both the affordance itself and the way it is perceived. Meaning constructed from perceptual cues (i.e., product semantics or semantics of the environment) can change the perception of affordances and make desired affordances perceptible or hide undesired ones. If perceiving affordances is only possible after exploration, it is important for designers to design for these exploratory actions (Stoffregen and Mantel 2015). Selecting perceptual cues and subsequently product semantics to trigger these explorative actions is crucial to promote the required perception of affordances. Affordances offered by tools, jigs, fixtures or the assembly environment (e.g., spatial cueing and clustering of components [Kirsh 1995]) can constrain or afford different actions, and are therefore important to facilitate efficient assembly. These affordances need to be aligned with work planning. As a result of this alignment, the context of assembly is potentially more controllable than the context of use, since users and the use environment are often unknown to the designer. It can help designers have an impact on, or even co-design, the assembly environment in which spatial arrangements, jigs and fixtures offer solutions that cannot be provided by components and subassemblies. However, more research is needed to make suggestions on how this cooperation can be established and which tasks are best assigned to product design or to work planning. Future research could also include experiments on how designers can implement DFAM most efficiently and how operators interact with the resulting assemblies. Research on how product designers can consider affordances most efficiently could include research on how new tools can be developed, implemented and validated, or how existing tools can be applied or adapted to fit the DFAM context. Other experiments could then focus on the proposed pathways to alter affordances (as illustrated in Fig. 4) and on how changes impact production and the assembly process. Also the formative analysis of work requirements could be an interesting future research topic (see Vicente [1999] on Cognitive Work Analysis). This could in relation to DFAM help operators create their own best way of working within the systems boundaries. Research on how DFAM can influence the context of use is also needed. A comparison between a complete and thorough redesign of a product with a focus on DFAM (i.e., where every aspect of the product is reconsidered) and its original product would be very valuable. Such a comparison could encompass performance, efficiency, cognitive load, but also the satisfaction of the operator during assembly. 
Table 2 Insights valuable for DFAM on meaning, design as communication, affordance and product semantics, based on literature review (Phases $1 \& 2$ ) and pilot studies (Phases $3 \& 4$ ).

\begin{tabular}{|c|c|c|}
\hline & Meaning & Phases \\
\hline M1 & $\begin{array}{l}\text { Operators construct meaning for assembly through interaction with multiple components and } \\
\text { subassemblies but also with tools, jigs and fixtures within an assembly environment. }\end{array}$ & $1,2,3$ \\
\hline M2 & $\begin{array}{l}\text { Designing meaning for assembly is not possible, promoting a desired interpretation of } \\
\text { components and subassemblies within the assembly environment is. }\end{array}$ & $1,2,3,4$ \\
\hline \multirow[t]{2}{*}{ M3 } & $\begin{array}{l}\text { Meanings can be afforded or discouraged physically by removing or adding constraints or } \\
\text { semantically (Krippendorff and Butter 2008). }\end{array}$ & 2 \\
\hline & Communication & \\
\hline $\mathrm{C} 1$ & $\begin{array}{l}\text { In many companies there is a double communication process from design to work planning and } \\
\text { from work planning to the operator both communicating the same message: how to assemble the } \\
\text { product. }\end{array}$ & 1 \\
\hline $\mathrm{C} 2$ & $\begin{array}{l}\text { Using components and subassemblies as media, might result in one communication process } \\
\text { which runs directly from designer to the operator. }\end{array}$ & $1,2,3,4$ \\
\hline \multirow[t]{2}{*}{$\mathrm{C} 3$} & $\begin{array}{l}\text { In a mature industry } 4.0 \text { assembly context, the assembly process is monitored, which allows } \\
\text { offering context and situationally- relevant information and support in order to correct errors } \\
\text { (Erol et al. 2016, Schuh et al. 2017). }\end{array}$ & 1 \\
\hline & Affordances & \\
\hline A1 & $\begin{array}{l}\text { If one action must follow on another action, the sequence of affordance perception is important } \\
\text { (Gaver 1991). }\end{array}$ & 2 \\
\hline A2 & $\begin{array}{l}\text { A real, perceived affordance can be undesired if it is useless to the operator at a given time and } \\
\text { when it diverts attention from another needed affordance at that same time. }\end{array}$ & $2,3,4$ \\
\hline A3 & $\begin{array}{l}\text { Making desired affordances perceptible and hiding undesired ones by lowering or raising their } \\
\text { perceptual threshold is possible when adding or removing perceptual cues (Lu and Cheng 2013). }\end{array}$ & 2 \\
\hline A4 & $\begin{array}{l}\text { When an affordance is not harmful, it is better to change an undesired perceptible affordance into } \\
\text { a hidden affordance by changing the perceptual cues than to transform it into a false affordance } \\
\text { by adding mechanical constraints. }\end{array}$ & $2,3,4$ \\
\hline A5 & $\begin{array}{l}\text { Changing hidden affordances in correct rejections by adding mechanical constraints can be } \\
\text { relevant when the affordance itself is potentially harmful. }\end{array}$ & 2,3 \\
\hline A6 & $\begin{array}{l}\text { Manual assembly is a complex action where both AAA's (artefact-artefact affordances) and } \\
\text { AUA's (artefact-user affordances) follow each other in a sequential and nested structure. }\end{array}$ & $1,2,3,4$ \\
\hline A7 & $\begin{array}{l}\text { In an assembly context, sequential and nested affordances are divided along components, } \\
\text { subassemblies, tools, jigs, fixtures and the environment. }\end{array}$ & $1,2,3$ \\
\hline A8 & $\begin{array}{l}\text { Due to its nested structure and sequential nature, correct assembly becomes impossible when a } \\
\text { needed affordance becomes unperceivable or unrealisable for the operator. }\end{array}$ & $2,3,4$ \\
\hline A9 & $\begin{array}{l}\text { Affordances are unrealisable for the operator if the designer overrates the capabilities of the } \\
\text { operator on a perceptual or on a physical level. }\end{array}$ & 3,4 \\
\hline \multirow[t]{2}{*}{ A10 } & $\begin{array}{l}\text { Spatial arrangements and clever placements in the assembly environment can strongly influence } \\
\text { the perception of affordance (Kirsh 1995). }\end{array}$ & 2 \\
\hline & Product semantics & \\
\hline S1 & $\begin{array}{l}\text { Perceptual cues can highlight how to grasp, orient, position and fixate a component or } \\
\text { subassembly on- or into another component or subassembly (product semantics in an assembly } \\
\text { context). }\end{array}$ & $2,3,4$ \\
\hline
\end{tabular}




\begin{tabular}{|c|l|c|}
\hline S2 & $\begin{array}{l}\text { Indicating how components need to be connected to each other can be achieved by highlighting } \\
\text { their shared connection. }\end{array}$ & $2,3,4$ \\
\hline S3 & $\begin{array}{l}\text { Components and component features can potentially become invisible and untouchable during } \\
\text { assembly, which opens up a range of possibilities to add perceptual cues that have meaning to the } \\
\text { operator without affecting the appearance of the end-product. }\end{array}$ & 3,4 \\
\hline S4 & $\begin{array}{l}\text { Dominant perceptual cues linked to component features can become invisible or untouchable } \\
\text { after the assembly of this specific component, which opens up possibilities for other perceptual } \\
\text { cues and perceptions of assembly sequence. }\end{array}$ & $2,3,4$ \\
\hline S5 & $\begin{array}{l}\text { Product metaphors applied on a component or subassembly level can support identification, } \\
\text { orientation and positioning of that component or subassembly within the assembly. }\end{array}$ & 2 \\
\hline S6 & $\begin{array}{l}\text { Product semantics can trigger the operator to engage in exploratory actions with different } \\
\text { components, eventually revealing desired sequential and nested affordances. }\end{array}$ & $2,3,4$ \\
\hline
\end{tabular}

\section{Conclusion}

This paper discusses the importance of DFAM in light of the increasing cognitive demands imposed on assembly operators today and the important drawbacks associated with the use of procedural assembly instructions. DFAM is all about designing products that support the operator in constructing an appropriate mental model of the assembly process when interacting with components, subassemblies, tools, jigs, fixtures and the assembly environment. This could increase the autonomy of the operator and decrease the need for procedural instructions. Moreover, in an Industry 4.0 assembly context, smart information systems will be able to give information on demand and monitor the assembly process to avoid or point out errors. This setting paves the way for approaches that foster the autonomy of the operator. Meaning, design as communication, affordances and product semantics were considered specifically within an assembly context (e.g., on the level of connections, components, subassemblies, tools, jigs, fixtures and the assembly environment) offering new insights to design for assembly meaning. The authors presented a first step towards DFAM and look forward to iterations on our proposed work, fostering operator well-being, work motivation and performance.

\section{References}

Agrawala M, Phan D, Heiser J, et al (2003) Designing effective step-by-step assembly instructions. ACM Trans Graph 22:828-837. https://doi.org/10.1145/882262.882352

Baber C, Parekh M, Cengiz TG (2014) Tool use as distributed cognition: How tools help, hinder and define manual skill. Front Psychol 5:1-14. https://doi.org/10.3389/fpsyg.2014.00116

Bley H, Reinhart G, Seliger G, et al (2004) Appropriate human involvement in assembly and disassembly. CIRP Ann Technol 53:487-509. https://doi.org/10.1016/s0007-8506(07)60026-2

Boess S, Kanis H (2008) Meaning in product use: a design perspective. In: Schifferstein HNJ, Hekkert P (eds) Product Experience. NY: Elsevier, New York, pp 305-332 https://doi.org/10.1016/B978-008045089-6.500150

Booker JD, Swift KG, Brown NJ (2005) Designing for assembly quality : strategies, guidelines and techniques. J Eng Des 16:279-295. https://doi.org/10.1080/09544820500126672

Boothroyd G (1994) Product design for manufacture and assembly. Comput Des 26:505-520. https://doi.org/10.1016/0010-4485(94)90082-5

Brolin A, Thorvald P, Case K (2017) Experimental study of cognitive aspects affecting human performance in manual assembly. Prod Manuf Res 5:141-163. https://doi.org/10.1080/21693277.2017.1374893

Carroll JM (1990) The Nurnberg funnel: designing minimalist instruction for practical computer skill. MIT press Cambridge, MA 
Castro-Alonso JC, Ayres P, Paas F (2016) Comparing apples and oranges ? A critical look at research on learning from statics versus animations. Comput Educ 102:234-243. https://doi.org/10.1016/j.compedu.2016.09.004

Chandler P, Sweller J (1991) Cognitive load theory and the format of instruction. Cogn Instr 8:293-332. https://doi.org/10.1207/s1532690xci0804_2

Chandler P, Sweller J (1992) The split-attention effect as a factor in the design of instruction. Br J Educ Psychol 62:233-246. https://doi.org/10.1111/j.2044-8279.1992.tb01017.x

Chandler P, Sweller J (1996) Cognitive load while learning to use a computer program. Appl Cogn Psychol 10:151170. https://doi.org/10.1002/(sici)1099-0720(199604)10:2<151::aid-acp380>3.0.co;2-u

Claeys A, Hoedt S, Soete N, et al (2015) Framework for evaluating cognitive support in mixed model assembly systems. IFAC-PapersOnLine 48:924-929. https://doi.org/10.1016/j.ifacol.2015.06.201

Cormier P, Olewnik A (2014) Toward a formalization of affordance modeling for engineering design. Res Eng Des 25:259-277. https://doi.org/10.1007/s00163-014-0179-3

Crilly N, Maier A, Clarkson PJ (2008) Representing artefacts as media: Modelling the relationship between designer intent and consumer experience. Int J Des 2:15-27

Dadashi N, Golightly D, Sharples S (2017) Seeing the woods for the trees : the problem of information inefficiency and information overload on operator performance. Cogn Technol Work 19:561-570. https://doi.org/10.1007/s10111-017-0451-1

Desmet PMA, Hekkert P (2002) The Basis of Product Emotions. In: Green W, Jordan P (eds) Pleasure with products, beyond usability. London: Taylor and Francis, pp 60-68

Eiriksdottir E, Catrambone R (2011) Procedural Instructions, Principles, and Examples: How to Structure Instructions for Procedural Tasks to Enhance Performance, Learning, and Transfer. Hum Factors 53:749-770. https://doi.org/10.1177/0018720811419154

Elmaraghy W, Elmaraghy H, Tomiyama T, Monostori L (2012) Complexity in engineering design and manufacturing. CIRP Ann - Manuf Technol 61:793-814. https://doi.org/10.1016/j.cirp.2012.05.001

Erol S, Jäger A, Hold P, et al (2016) Tangible Industry 4.0: A Scenario-Based Approach to Learning for the Future of Production. Procedia CIRP 54:13-18. https://doi.org/10.1016/j.procir.2016.03.162

Fast-Berglund Å, Fässberg T, Hellman F, et al (2013) Relations between complexity, quality and cognitive automation in mixed-model assembly. J Manuf Syst 32:449-455. https://doi.org/10.1016/j.jmsy.2013.04.011

Fu W, Gray WD (2006) Suboptimal tradeoffs in information seeking. Cogn Psychol 52:195-242. https://doi.org/10.1016/j.cogpsych.2005.08.002

Ganier F (2004) Factors affecting the processing of procedural instructions: implications for document design. IEEE Trans Prof Commun 47:15-26. https://doi.org/10.1109/tpc.2004.824289

Ganier F, De Vries P (2016) Are instructions in video format always better than photographs when learning manual techniques? The case of learning how to do sutures. Learn Instr 44:87-96. https://doi.org/10.1016/j.learninstruc.2016.03.004

Gaver W (1991) Technology affordances. In: Proceedings of the SIGCHI conference on Human factors in computing systems. ACM. https://doi.org/10.1145/108844.108856

Gibson JJ (1979) The Ecological Approach to Visual Perception. Boston: Houghton Miffin

Ginns P (2006) Integrating information : A meta-analysis of the spatial contiguity and temporal contiguity effects. Learn Instr 16:511-525. https://doi.org/10.1016/j.learninstruc.2006.10.001

Heiser J, Phan D, Agrawala M, et al (2004) Identification and validation of cognitive design principles for automated generation of assembly instructions. In: Proceedings of the working conference on Advanced Visual Interfaces. ACM, pp 311-319

Hekkert P, Cila N (2015) Handle with care! Why and how designers make use of product metaphors. Des Stud 40:196-217. https://doi.org/10.1016/j.destud.2015.06.007 
Höffler TN, Leutner D (2007) Instructional animation versus static pictures : A meta-analysis. Learn Instr 17:722738. https://doi.org/10.1016/j.learninstruc.2007.09.013

Hollnagel E (2012) Coping with complexity : past , present and future. Cogn Technol Work Work 14:199-205. https://doi.org/10.1007/s10111-011-0202-7

Hu SJ, Zhu X, Wang H, Koren Y (2008) Product variety and manufacturing complexity in assembly systems and supply chains. CIRP Ann - Manuf Technol 57:45-48. https://doi.org/10.1016/j.cirp.2008.03.138

Huff M, Bauhoff V, Schwan S (2012) Effects of split attention revisited: A new display technology for troubleshooting tasks. Comput Human Behav 28:1254-1261. https://doi.org/10.1016/j.chb.2012.02.008

Johansson PEC, Enofe MO, Schwarzkopf M, et al (2017a) Data and Information Handling in Assembly Information Systems - A Current State Analysis. In: Procedia Manufacturing. 11: 2099-2106. https://doi.org/10.1016/j.promfg.2017.07.335

Johansson PEC, Eriksson G, Johansson P, et al (2017b) Assessment Based Information Needs in Manual Assembly. In: DEStech Transactions on Engineering and Technology Research (Icpr). pp 366-371.

Judge TA, Heller D, Mount MK (2002) Five-Factor Model of Personality and Job Satisfaction : A Meta-Analysis. J Appl Psychol 87:530-541. https://doi.org/10.1037//0021-9010.87.3.530

Kalyuga S, Chandler P, Sweller J (1998) Levels of Expertise and Instructional Design. Hum Factors 40:1-17. https://doi.org/10.1518/001872098779480587

Kalyuga S, Chandler P, Sweller J (2004) When redundant on-screen text in multimedia technical Instruction can interfere With learning. Hum Factors J Hum Factors Ergon Soc 46:567-581. https://doi.org/10.1518/hfes.46.3.567.1640

Kapkin E (2015) Meaning Attribution Model of Product Forms: A Holistic Approach. Norh Carolina State University

Kirsh D (1995) The intelligent use of space. Artif Intell 73:31-68. http://dx.doi.org/10.1016/0004-3702(94)00017-U

Klein G (2008) Naturalistic Decision Making. Hum Factors 50:456-460. https://doi.org/10.1518/001872008x288385

Knapheide C (2000) Synergy and subsidiarity: The systematic determination of software, user, and operating instructions. Int J Hum Comput Interact 12:415-430. https://doi.org/10.1080/10447318.2000.9669068

Krippendorff K (1989) On the Essential Contexts of Artifacts or on the Proposition that "Design Is Making Sense (of Things).” Des Issues 5:9-39. https://doi.org/10.2307/1511512

Krippendorff, K., \& Butter, R (1984). Product semantics: Exploring the symbolic qualities of form. Innovation, 3(2), 4-9. Retrieved from http://repository.upenn.edu/asc_papers/40

Krippendorff K, Butter R (1993) Where meanings escape functions. Des Manag J 4:30-37. https://doi.org/10.1111/j.1948-7169.1993.tb00134.x

Krippendorff K, Butter R (2008) Semantics: Meanings and Contexts of Artifacts. In: H. N. J. Schifferstein, Hekkert P (eds) Product Experience. NY: Elsevier, New York, pp 353-376. https://doi.org/10.1016/B978-008045089$6.50017-4$

Kroes P (2002) Design methodology and the nature of technical artefacts. Des Stud 23:287-302. https://doi.org/10.1016/s0142-694x(01)00039-4

Loch F, Quint F, Brishtel I (2016) Comparing video and augmented reality assistance in manual assembly. In: Proceedings - 12th International Conference on Intelligent Environments, IE 2016. pp 147-150

Longo F, Nicoletti L, Padovano A (2017) Smart operators in industry 4.0: A human-centered approach to enhance operators' capabilities and competencies within the new smart factory context. Comput Ind Eng 113:144-159. https://doi.org/10.1016/j.cie.2017.09.016

Lu J, Cheng L (2013) Perceiving and Interacting Affordances : A New Model of Human - Affordance Interactions. Integr Psychol Behav Sci 47:142-155. https://doi.org/10.1007/s12124-012-9202-2

Maier JRA, Fadel GM (2009) Affordance based design : a relational theory for design. Res Eng Des 20:13-27. 
https://doi.org/10.1007/s00163-008-0060-3

Matthews G, Campbell SE, Falconer S, et al (2002) Fundamental Dimensions of Subjective State in Performance Settings : Task Engagement, Distress, and Worry. Emotion 2:315-340. https://doi.org/10.1037//15283542.2.4.315

Mattsson S, Fast-Berglund (2016) How to Support Intuition in Complex Assembly? Procedia CIRP 50:624-628. https://doi.org/10.1016/j.procir.2016.05.014

Mattsson S, Fasth Berglund A, Li D, Thorvald P (2018) Forming a cognitive automation strategy for Operator 4.0 in complex assembly. Comput Ind Eng. https://doi.org/10.1016/j.cie.2018.08.011

Mattsson S, Karlsson M, Fast-Berglund A, Hansson I (2014) Managing production complexity by empowering workers: Six cases. In: Procedia CIRP. Elsevier B.V., pp 212-217 https://doi.org/10.1016/j.procir.2014.02.041

McGrath JE (1976) Stress and behavior in organizations. In: Dunnette, Marvin D (ed) Handbook of industrial and organizational psychology. Rand McNally \& Co, Chicago, pp 1351-1396

Mowday RT, Porter LW, Steers RM (2013) Employee—organization linkages: The psychology of commitment, absenteeism, and turnover. Academic press

Norman D (1988) The psychology of everyday things. Basic books New York

Norman D (1999) Affordance, conventions, and design. interactions 6:38-43. https://doi.org/10.1145/301153.301168

Osiurak F, Badets A (2016) Tool Use and Affordance : Manipulation-Based Versus Reasoning-Based Approaches. Psychol Rev 123:534-568. https://doi.org/10.1037/rev0000027

Parmentier DD, Detand J, Saldien J (2019) Designing products with a focus on self-explanatory assembly, a case study. In: Proceedings of the 22nd international conference on engineering design (ICED19), pp 2081-2090. https ://doi.org/10.1017/dsi.2019.214

Pine BJ (1993) Mass customization: the new frontier in business competition. Harvard Business School Press, Boston

Pols AJK (2012) Characterising affordances: The descriptions-of-affordances-model. Des Stud 33:113-125. https://doi.org/10.1016/j.destud.2011.07.007

Radkowski R, Herrema J, Oliver J (2015) Augmented reality-based manual assembly support with visual features for different degrees of difficulty. Int J Hum Comput Interact 31:337-349.

https://doi.org/10.1080/10447318.2014.994194

Rasmussen J (2000) Human factors in a dynamic information society : where are we heading ? Ergonomics 43:869879. https://doi.org/10.1080/001401300409071

Re GM, Oliver J, Bordegoni M (2016) Impact of monitor-based augmented reality for on-site industrial manual operations. Cogn Technol Work 18:379-392. https://doi.org/10.1007/s10111-016-0365-3

Redström J, Grauers H (2006) Towards user design? On the shift from object to user as the subject of design. Des Stud 27:123-139. https://doi.org/10.1016/j.destud.2005.06.001

Rettig M (1991) Nobody Reads Documentation. Commun ACM 34:19-24. https://doi.org/10.1145/105783.105788

Ryan RM, Deci EL (2000) Self-determination theory and the facilitation of intrinsic motivation, social development, and well-being. Am Psychol 55:68-78. https://doi.org/10.1037//0003-066x.55.1.68

Schuh, G., Anderl, R., Gausemeier J., ten Hompel, M., Wahlster, W. (Eds.): Industrie 4.0 Maturity Index. Managing the Digital Transformation of Companies (acatech STUDY), Munich: Herbert Utz Verlag 2017

Schumacher P (2007) Creating effective illustrations for pictorial assembly instructions. Inf Des J 15:97-109. https://doi.org/10.1075/idj.15.2.01sch

Schumacher P (2013) A Pattern Language for Pictorial Assembly Instructions ( PAIs ). Inf Des J 20:111-135. https://doi.org/10.1075/idj.20.2.03sch

Shannon CE, Weaver W (1949) The mathematical theory of communication. University of Illinois Press, Urbana, IL 
Siu KWM (2003) Users' creative responses and designers' roles. Des Issues 19:64-73. https://doi.org/10.1162/074793603765201424

Stoffregen TA, Mantel B (2015) Exploratory movement and affordances in design. Artif Intell Eng Des Anal Manuf 29:257-265. https://doi.org/10.1017/s0890060415000190

Stork S, Schubö A (2010) Human cognition in manual assembly: Theories and applications. Adv Eng Informatics 24:320-328. https://doi.org/10.1016/j.aei.2010.05.010

Sweller J, van Merrienboer JJG, Paas FG (1998) Cognitive architecture and instructional design. Educ Psychol Rev 10:251-296. https://doi.org/10.1023/a:1022193728205

Syberfeldt A, Danielsson O, Holm M, Wang L (2015) Visual assembling guidance using augmented reality. Procedia Manuf 1:98-109. https://doi.org/10.1016/j.promfg.2015.09.068

Um J, Lyons A, Lam HKS, et al (2017) Product variety management and supply chain performance: A capability perspective on their relationships and competitiveness implications. Int J Prod Econ 187:15-26. https://doi.org/10.1016/j.ijpe.2017.02.005

Van Acker BB, Parmentier DD, Vlerick P, Saldien J (2018) Understanding mental workload: from a clarifying concept analysis toward an implementable framework. Cogn Technol Work 20:351-365. https://doi.org/10.1007/s10111-018-0481-3

Vanderhaegen F, Carsten O (2017) Can dissonance engineering improve risk analysis of human-machine systems? Cogn Technol Work 19:1-12. https://doi.org/10.1007/s10111-017-0405-7

Vera D, Crossan M, Rerup C, Werner S (2014) “Thinking Before Acting” or “Acting Before Thinking”: Antecedents of Individual Action Propensity in Work Situations. J Manag Stud 51:603-633. https://doi.org/10.1111/joms.12075

Vicente, KJ (1999) Cognitive work analysis: Toward safe, productive, and healthy computer-based work. Lawrence Erlbaum Associates. Mahwah, NJ

Vihma S (1995) Products as representations: A semiotic and aesthetic study of design products, 1ste editi. University of Art and Design Helsinki

Wan X, Sanders NR (2017) The negative impact of product variety: Forecast bias, inventory levels, and the role of vertical integration. Int J Prod Econ 186:123-131. https://doi.org/10.1016/j.ijpe.2017.02.002

Whittington JL, Meskelis S, Asare E, Beldona S (2017) Creating Meaning in Work through Job Enrichment. In: Enhancing Employee Engagement. Palgrave Macmillan, Cham, pp 43-51

Wieringa D, Moore C, Barnes V (1998) Procedure writing: principles and practices. IEEE

Wilson JR, Corlett EN (1995) Evaluation of human work: A Practical Ergonomics Methodology, 2nd and Re. Taylor $\&$ Francis, London

Wong A, Marcus N, Ayres P, et al (2009) Instructional animations can be superior to statics when learning human motor skills. Comput Human Behav 25:339-347. https://doi.org/10.1016/j.chb.2008.12.012

You H, Chen K, Kung NC (2007) Applications of affordance and semantics in product design. Des Stud 28:23-38. https://doi.org/10.1016/j.destud.2006.07.002

Young M, Brookhuis K, Wickens C, Hancock P (2015) State of science: mental workload in ergonomics. Ergonomics 58:1-17. https://doi.org/10.1080/00140139.2014.956151 